\section{Design social e solidário aplicado em práticas cotidianas: metodologias interdisciplinares em ensino, pesquisa e extensão}

Ana Beatriz Pereira de Andrade * e Henrique

Perazzi de Aquino **

Resumen: El presente artículo pone en escena los principios del Diseño Social aplicados a la Enseñanza, Investigación y Extensión. Se considera la práctica proyectual como actividad-fin en Diseño. De este modo, la opción de la acción didáctico-pedagógica en el camino del Diseño Social propone una actitud para el desarrollo de productos junto a grupos sociales, y no para grupos sociales. Reconocido el carácter multidisciplinario e híbrido del Diseño, la investigación recurre a bases teóricas en áreas distintas. Ejemplifica resultados en proyectos concretos desarrollados y validados por estudiantes del "Curso de Graduação em Design FAAC/UNESP” entre los años de 2012 y 2014.

Palabras clave: Enseñanza en Diseño - Disciplinas de Proyecto - Reformulación Curricular.

[Resúmenes en inglés y portugués en la página 293]

${ }^{(*)}$ Profesora Doctora en el Departamento de Diseño de la Universidad Estadual Paulista e investigadora en Diseño. PhD en Psicología Social, Máster en Comunicación y Cultura, Graduada en Comunicación Visual. Colabora en actividades de gestión, pesquisa y extensión. Actúa como representante junto a la Secretaría Nacional de Ciencia y Tecnología, Coordinadora Científica del Núcleo de Estudios del Negro en la UNESP e integra el Grupo de Investigación en Diseño Contemporáneo (CNPq / UNESP).

${ }^{(* *)}$ Jornalista. Máster en Comunicación (en curso). Graduado en Historia. Colabora en actividades culturales de la ciudad de Bauru. Publica en periódicos locales y nacionales.

\title{
Introdução
}

Um dos pontos de partida é a livre escolha do tema e do recorte quanto ao objeto de estudo. Acredita-se que este passo promove o comprometimento dos futuros profissionais em Design com os interlocutores. O projeto não tem início na intenção de um produto, mas na vivência do processo projetual. Assim, o processo de pesquisa e o desenvolvimento do produto final têm importância igualitária.

Considerado o tripé Ensino, Pesquisa e Extensão, apresentam-se processos e resultados práticos com aplicação da metodologia e ferramentas em Design Social. 
Em Ensino, destacam-se três experiências em disciplina obrigatória de graduação (Metodologia de Projeto, oferecida no $5^{\circ}$ termo), um exemplo de desenvolvimento de Identidade Visual (disciplina Projeto II, oferecida no $6^{\circ}$ termo) e um exemplo em Trabalho de Conclusão de Curso (TCC).

No campo da Pesquisa foram eleitos três exemplos em Iniciação Científica (alunos de $3^{\circ}$ / $4^{\text {o }}$ semestre - dois bolsistas CNPq - http://www.cnpq.br/ )

Para Extensão cabe ressaltar o Labsol (Laboratório em Design Solidário), coordenado pelo Professor Doutor Claudio Roberto y Goya (2011) cuja proposta sempre foi consonante com os princípios e práticas do Design Social.

Consideram-se como desdobramentos inserção no mercado de trabalho, produções acadêmico-científicas e projeto prático desenvolvido em comunidade com resultado público na cidade de Bauru.

Por fim, a guisa de conclusões, aponta-se possíveis desdobramentos e reflexões acerca da diversidade de possibilidades metodológicas de projetos em Design em constante mutação.

\section{Ensino}

Os projetos descritos a seguir foram selecionados conforme adequação do que se trata nesta exposição. São resultados de processos propostos em disciplinas sob a responsabilidade de uma das autoras do presente artigo.

Foi proposto para a turma cursando Metodologia do Projeto o desafio da prática do Design Social. A disciplina é introdutória, e pré-requisito, para os projetos subsequentes na estrutura curricular do Curso de Graduação em Desenho Industrial. No caso, foi ministrada para os estudantes com a escolha pela habilitação em Design Gráfico.

O Instituto Yauaretê é um Ponto de Cultura sediado em Bauru, para maiores informações acesse http://www.culturaviva.net.br/. Trabalha com pesquisa e documentação histórica, voltados principalmente para o resgate e preservação da Cultura Tradicional, Folclore, Cultura Cabocla, Povos Indígenas da Amazônia, Patrimônio Histórico, Cultura Negra, dentre outros segmentos. Atua também na denominada Grande Região que vem a ser o conjunto de municípios ao redor, vinculados a Bauru por questões socioculturais e econômicas.

A equipe identificou a possibilidade do desenvolvimento de um projeto de Identidade Visual. Aliás, conceito iminente ao propósito de Yauaretê. O interlocutor foi Seu Tito (Tito Pereira), fundador e coordenador do Ponto de Cultura.

A interdisciplinaridade ao longo do processo deu-se em interface com linguística, considerada a singularidade da etimologia da palavra Yauaretê, bem como com reflexões acerca de conceitos em cultura.

No que tange ao aspecto técnico e estético, debruçaram-se nas teorias das cores e das formas, sempre em contato e conversas com o interlocutor.

Ao término do processo, o produto final incluiu, além da Identidade Visual, aplicações em projeto gráfico de capas para DVD que põem em destaque especificidades culturais de algumas das cidades que o Ponto de Cultura abrange em termos de atuação -algo que se afina com a proposta em Design Social. 
Na sequência, relata-se o estudo de caso prático junto da ONG Naturae Vitae, para maiores informações acesse http://www.naturaevitae.org/

A ONG foi fundada por três estudantes de biologia da UNESP (2002), campus de Bauru. A intenção inicial era a de unir universidade e sociedade com o intuito de proteger a grande área de vegetação de cerrado que a cidade de Bauru possui. Ao longo dos anos, nossa atuação foi se diversificando e as ações ganharam credibilidade junto à sociedade bauruense.

Atualmente é uma Sociedade de Proteção Animal e Ambiental que atua ativamente contra maus-tratos aos animais e degradação do meio ambiente, tornando-se sinônimo de luta contra o desrespeito e a impunidade. Um dos objetivos é o de lutar para que os maustratos sejam considerados crime passível de punição. A proposta não é a de recolher nem abrigar os animais, mas a de prover os devidos cuidados em lares provisórios até o momento de adoção.

Adoção é temática polêmica, ainda mais quando se trata de animais. Assim começou o projeto da equipe de quatro meninas, com alguma ascendência japonesa.

Inseridas nesse universo, as meninas quase enlouqueceram diante da diversidade de questões presentes. Conseguiram, por escolha, dedicar-se ao aspecto da família. Pesquisaram e obtiveram informações de que a atitude de adotar um animal parte das crianças ou dos idosos. Identificaram a importância em manter o animal com saúde e qualidade de vida. Considerando suas origens étnicas, por isso a menção do fato de serem descendentes de japoneses, bem como é fato que o interior de São Paulo é foco de imigração nipônica, os resultados contêm elementos culturais desta origem.

Desenvolveram produtos interativos. Paper toys, bonecos e folhetos. Personagens e instruções para montagem foram representados e produzidos graficamente, bem como divulgados via internet.

Declararam as alunas, em Relatório Final, a validade da experiência vivida, destacando a possibilidade da ampliação da prática profissional e sua aplicabilidade. Também verificaram a importância do compromisso, respeito, cumprimento de etapas projetuais, prazos e seriedade.

Partindo do interesse pelo meio ambiente e sustentabilidade, após muitas tentativas (o que é natural no processo de identificação e integração ao contexto real), uma equipe dedicouse a COOTRAMAT. A cooperativa, composta por 24 pessoas, faz a coleta e separação de plásticos, papéis, vidros e lixos orgânicos, descartados pela população da cidade de Bauru. Vivenciando a realidade concreta e as possibilidades físicas, técnicas e tecnológicas dos interlocutores, o desejo inicial em desenvolver um site foi eliminado. Os alunos tiveram a oportunidade de exercitar habilidades fotográficas em pesquisa de campo, vivenciando uma realidade diferenciada de seus cotidianos. Aprendendo, buscando referências cientificamente certificadas, com orientação docente e com responsabilidade social, desenvolveram um logotipo -seguindo o que é determinado no Brasil para caracterizar uma cooperativa- e um folheto. $\mathrm{O}$ folheto tem a intenção de apresentar à população local o funcionamento e as práticas da COOTRAMAT a fim de que o índice de 3\% da possibilidade de reciclagem do descarte de lixo em Bauru possa atingir, minimamente, 10\%.

Cabe mencionar que os interlocutores estiveram presentes no momento das apresentações dos resultados da disciplina Metodologia de Projeto. 
Na disciplina Projeto II, destaca-se o resultado na Casa da Capoeira. Em Bauru o ápice da capoeira ocorre em 1998, com alguns grupos com grande número de praticantes, projetos sociais em andamento nas cidades da região dinamizados pelos vários grupos e com apoio das municipalidades e grandes eventos de graduação e batizados.

A equipe de alunos conviveu com os partícipes de um local que elege a capoeira como forma de sociabilidade e ocupação de tempo livre para qualquer cidadão. A pesquisa multicultural acerca do tema os levou a busca de origens históricas, étnicas e a pesquisas cinematográficas e bibliográficas. O desenhar, a partir do movimento corporal, foi fundamental ao longo do processo. Consultando outras orientações, de docentes reconhecidamente especializados em desenho, expressão e representação plástica, definiram uma marca. O interlocutor foi Pereira, fundador da Casa da Capoeira.

Segundo o historiador e pesquisador bauruense Aquino (2013):

O nome completo é pomposo, Alberto de Carvalho Pereira Sobrinho, 48 anos, assim como a altivez do que levantou na vila Engler, pertinho do Camélias, a Casa da Capoeira de Bauru, um local moderno e cheio de vida, com a sua cara. Quando bancário vivia sem percalços na estrutura do Banespa, mas na transformação para Santander, não deu mais, fez um acordo e com o valor recebido, idealizou como queria ver edificado o seu sonho. Colocou tudo o que ganhou ali, algo só possível para os idealistas, pois sempre teve ciência de que dali não sairia rico, nem era essa sua pretensão. Buscava a felicidade, fazer o que sempre gostou e conciliar o trabalho com a capoeira. A casa foi levantada, imponente, pilares bem altos, paredes de tijolo à vista e um local de congraçamento coletivo. Diariamente passa ali a maior parte do seu tempo (segunda a sexta, das $19 \mathrm{~h}$ às $21 \mathrm{~h}$ ), dividindo com a atividade de professor de Educação Física, ministrada em Escolas Públicas e na Facol. Vê-lo rodeado dos alunos, ao lado da praça, inaugurada em agosto de 2011, que batalhou para que tivesse o nome atual, Mestre Bimba, pode ser considerado uma pessoa realizada. Realizada, mas em constante busca. Os percalços ocorrem a todo instante, nada que o faça esmorecer. Trata igualmente o filho do industrial como o menino de rua, que espia suas aulas das janelas. Sofre mesmo é pela perda de valiosos garotos, bem fundamentados no esporte, ainda se afastando por causa da influência religiosa, vendo no batuque e na ligação com candomblé elos de diabólicas influências. Não é de reclamar (é dos que vão à luta), a própria fleuma em pessoa, mas é visível a percepção de que o poder público poderia fazer um bocadinho mais, entender o real significado da capoeira e nas vésperas dos Jogos Abertos na cidade demonstrar maior apreço a esse esporte. Alberto segue fazendo de sua vida uma bela lição de dedicação e apreço a um ideal. Ele é a capoeira na cidade. (Aquino, 2013)

Segue depoimento do interlocutor: 
O processo de criação da marca da Casa da Capoeira de Bauru foi muito intenso e profundo. Os estudantes da Unesp, responsáveis pelo desenho, ao mesmo tempo em que buscavam signos e significados nos elementos da Capoeira Regional, que são o objeto do nosso trabalho, nos instigavam a pensar em quais eram os nossos elementos identitários, o que nos caracterizava e diferenciava dos demais grupos de capoeira, nessa nossa proposta de construir esse grupo institucionalmente organizado e nos nossos passos em direção ao futuro da Casa da Capoeira de Bauru e da própria capoeira, nessa nossa ação local articulada com a capoeiragem no Brasil e no mundo. (Pereira Sobrinho, 2014)

Além da marca, a equipe desenvolveu um site de uma forma que possa ser atualizado pelos membros organizadores da Casa da Capoeira. Esse resultado fez parte de um projeto desenvolvido na modalidade Iniciação Científica que será aqui apresentado, fortalecendo a interface entre ensino e pesquisa.

Destaca-se em Projeto de Conclusão de Curso (TCC) intitulado Somos Todos Um desenvolvido junto a Escola Viver - Waldorf de Bauru/SP, para maiores informações acesse https://escolaviver.wordpress.com/aviver/

No Resumo do Relatório Final a autora diz:

Com o objetivo principal de trazer boas energias aos que com ele tenham contato, de uma forma simples e leve, Somos Todos Um apresenta-se como um projeto baseado em estudos em Natureza, Simplicidade e Espiritualidade, com enfoque nas crianças da Escola Viver - Waldorf de Bauru/SP. Amor, Afeto, Cuidado, Respeito, Filosofia, Sociologia, Pedagogia, dentre outros saberes e sabores misturam-se e interligam-se em uma rica Teia repleta de trocas, experiências e evolução. (Ferrari, 2013, p. 23)

Em síntese, houve identificação da interlocutora: a professora Elaine Facchim, responsável pelas aulas de música. Esses contatos foram fundamentais para o entendimento da aluna acerca dos princípios teóricos norteadores do grupo social: a pedagogia Waldorf e a Antroposofia.

A Escola Viver - Waldorf de Bauru/SP oferece ensino nos níveis infantil, fundamental e médio e atende cerca de 300 alunos. Após o recorte em uma das turmas, em visitas regulares foram aplicadas ferramentas práticas do Design Social.

A paixão e a habilidade da pesquisadora por fotografia, aliadas ao fato de que foi identificado interesse pelo grupo registrar as atividades diárias, deram origem a um ensaio fotográfico.

As imagens captadas retrataram os princípios da pedagogia Waldorf e tiveram uso para acompanhamento do cotidiano das crianças por parte dos pais.

O produto final alcançou o principal objetivo identificado: o de compartilhar alegria com um sentimento de simplicidade e leveza, criando uma atmosfera de energia positiva. 


\section{Pesquisa}

Descrevem-se três sínteses de projetos de pesquisa, metodologicamente pautados em Design Social. Todas com concessão de bolsas PIBITI e/ou PIBIC. A signatária deste Relatório responde pela função de Orientadora.

A pesquisa $\mathrm{O}$ Hijab e a Mulher Muçulmana: uma relação de liberdade, moda e religião foi desenvolvida em Iniciação Científica (PIBITI - bolsa CNPq) com caráter teórico-prático, considerando aplicação e usabilidade reais. Um dos objetivos foi o de compreender questões sociais e culturais relacionadas ao uso do véu pelas mulheres muçulmanas, pertinentes ao desenvolvimento de uma linha de hijab para a comunidade islâmica brasileira jovem, especificamente estabelecida na cidade de Bauru.

As interlocutoras, um grupo de jovens descendentes, acompanharam todo o projeto de pesquisa.

Foram investigados aspectos das relações entre a religiosidade e o uso do hijab, demonstrando as múltiplas possibilidades de relacionamento da mulher muçulmana com esse tipo de véu, como um dos elementos para o Design da linha de hijab no campo do Design em Moda. Buscou-se uma compreensão e entendimento das relações entre a mulher muçulmana e o véu, com aprofundamento em aspectos socioculturais.

A partir de pesquisas e aplicação de métodos e ferramentas, o resultado foi o desenvolvimento de uma linha de hijabs destinada às mulheres muçulmanas, descendentes, com recorte em inspiração na geografia do cerrado.

A linha de hijabs foi inspirada em animais e flores do cerrado. As escolhas foram: Flor de maracujá do cerrado; Flor de São Miguel; Chuveirinho; Raposa do cerrado; Veado-campeiro e Tamanduá-bandeir. A Voz da Capoeira: cartografia de uma experiência em Design Social aplicada em jornal comunitário foi também Iniciação Científica (bolsa PIBIC).

A pesquisa resultou no desenvolvimento e produção do jornal comunitário A Voz da Capoeira. Foi elaborado junto com o Centro Cultural Casa da Capoeira, localizado na cidade de Bauru. Optou-se pelos princípios do Design Social, considerando como interlocutores: fundador, professores e alunos.

A escolha do espaço deu-se a partir da verificação de que a prática do grupo social específico adota uma visão acerca da Capoeira Regional que vai além da luta e do jogo.

Constatou-se que a filosofia da Casa da Capoeira inclui aplicação concreta dos princípios da capoeira em situações do cotidiano. Os ideais presentes nas atividades e ações difundidas pelo grupo inserem-se em questões da cidade de Bauru, promovendo possibilidades de transformação social e cultural.

Foi, então, esse um dos motivos de desenvolver o jornal comunitário. Não apenas como material gráfico impresso para divulgação, mas como registro de ação e difusão de ideias. A Multidisciplinaridade fez-se presente no campo teórico, em razão da diversidade de referencial necessário, e na prática em virtude do fato de que o resultado prático pretendido foi desenvolvido em conjunto com pesquisadores-alunos de Jornalismo da FAAC/UNESP. Foram produzidas três edições, com tiragem de 10 mil exemplares, o que permitiu avaliação e análise de resultados. O envolvimento do grupo social em todas as etapas do processo indicou a opção metodológica da cartografia para descrever o projeto enfatizando as relações entre Design e Emoção. 
Ainda em fase inicial, Velhas Lembranças, Memórias de Vida (bolsa PIBITI CNPq) é pesquisa com o seguinte resumo:

A presente pesquisa teve início a partir de estudo da trajetória e obra da fotógrafa Annie Leibovitz. O objeto de estudo é o de promover a visibilidade, sob forma de imagens fotográficas e de registros de memória oral as lembranças, memórias e sentimentos de idosos. O recorte se dá na cidade de Bauru, interior de São Paulo, especificamente junto a idosos abrigados em uma instituição filantrópica sem fins lucrativos. Trata-se da Associação Beneficente Cristã, conhecida como Paiva. Pretende-se, com a pesquisa, registrar as lembranças e memórias de vida dos idosos, abordando aspectos históricos e relatos orais dos mesmos. A proposta que se apresenta é a do desenvolvimento de um projeto teórico-prático com o uso de fotografia e textos resultantes tanto das reflexões provenientes de referencial teórico, quanto de resultados de relatos de memórias orais dos interlocutores. Para a construção do registro imagético e iconográfico a metodologia é a da cartografia e da Teoria do Ator Rede. Um princípio a ser adotado ao longo do processo, ainda em fase de investigação é o do Design Social que, em sua origem propõe o pesquisar junto com alguém e não para alguém. (Melara, 2014, p. 12)

\section{Extensão}

No caso de abordagem em Extensão, optou-se por exemplificar o Labsol. Considera-se um exemplo de prática processual e obtenção de resultados relacionados com princípios do Design Social.

O Projeto de Extensão Labsol, Laboratório de Solidariedade, é vinculado ao Departamento de Design da FAAC. A Coordenação é do Professor Doutor Goya (2011). Possui como principal proposta o desenvolvimento de ações conjuntas entre o Design e as comunidades. Os projetos são desenvolvidos em parceria e, por vezes, agregam valor ao que já é desenvolvido e aos processos de produção.

O Labsol tem base em um tripé constituído pelos conceitos de Sustentabilidade, Ecodesign e Economia Solidária. Tem por filosofia despertar no aluno do curso de Design a possibilidade da aplicação de conhecimento a serviço de uma sociedade mais democrática e solidária. A intenção é a de não apenas produzir a serviço do capital, mas a de considerar o bem comum.

Desde 2007, o Labsol tem por objetivos: otimizar, revitalizar e qualificar a produção comunitária com base no tripé conceitual.

A formação dos integrantes do Labsol é continua e as ações levam em conta as perspectivas de qualidade estética e produtiva, em alguns casos considerando a autonomia na geração de renda das comunidades.

Em encontros, os alunos aprendem métodos e técnicas utilizados pela comunidade, pesquisam referências bibliográficas e visuais relacionadas e aplicam ferramentas metodológicas de pesquisa. 
Entende-se todo o processo como um aprendizado de mão dupla, da troca de saberes, em que os membros do laboratório aprendem da comunidade dados de sua cultura e de seus modos de fazer.

Além dos estudantes em Design, o Labsol integra alunos do Curso de Comunicação Social e Engenharia de Produção. Recentemente, iniciou parceria com o Projeto de Extensão NeoCriativa -Núcleo de Estudos e Observação em Economia Criativa- que tem coordenação do Professor Doutor Juarez Xavier.

\section{Desdobramentos}

Os projetos apresentados desenvolvidos como atividades de Ensino resultaram em inserção dos alunos no mercado de trabalho. Após os resultados produzidos com a finalidade de cumprir os requisitos das disciplinas, os alunos envolvidos permaneceram (alguns ainda permanecem) em atividade de prestação de serviços para os grupos sociais com os quais se relacionaram ao longo dos processos projetuais.

Quanto às atividades de pesquisa, registra-se ampla participação em importantes fóruns acadêmico-científicos com 100\% de aprovação e geração de publicações. Destacam-se: Congreso de Enseñanza de Diseño, Encuentro Latinoamericano de Diseño, Encuentro Latinoamericado de Moda (Universidade de Palermo, Buenos Aires, Argentina), Colóquio de Moda (edição nacional e internacional), Congresso Brasileiro de Pesquisa e Desenvolvimento em Design (P\&D), Ergotrip Design, Seminário Mídia e Cidadania (UNESP), Congresso Internacional de Design da Informação (CIDI) e Intercom Sudeste, dentre outros. No que diz respeito à extensão, há dois anos o Labsol, em parceria com o NeoCriativa, é responsável por projeto e desenvolvimento da apresentação do Grêmio Recreativo Escola de Samba Coroa Imperial da Grande Cidade no Carnaval de Bauru junto com a comunidade do Núcleo Geisel (bairro da cidade).

"Todas as fantasias e alegorias apresentadas foram executadas na cidade de Bauru, por alunos da UNESP junto com a Comunidade da Coroa Imperial, desenvolvendo talentos e, principalmente, preservando e valorizando os modos de fazer e a cultura local". (Goya, 2011, p. 22)

Fundada em 1992, a Coroa Imperial é uma escola de samba movida por um grupo familiar tradicional do bairro Núcleo Residencial Presidente Geisel. A integração entre a família, a escola e o bairro é tão orgânica e natural que suas histórias se confundem e se constroem mutuamente. Nesse sentido, Olivia Arantes de Souza, o alicerce da comunidade e a principal interlocutora, membro da escola de samba e presidente do Centro Comunitário do Geisel, ressalta como o samba se uniu à grandeza do laço familiar.

Eu e minhas irmãs sempre fomos carnavalescas, desfilávamos na Escola de Samba Mocidade Independente de Vila Falcão. Com a construção do Sambódromo, decidimos que não tinha sentido desfilar em outro bairro tendo um sambódromo no fundo do nosso quintal. Minha filha já nasceu no samba! (Souza, 1996) 
Ana de Barros, matriarca da Coroa Imperial e mãe de Dona Olivia, batizou a escola com o nome de uma planta, a qual só floresce uma vez por ano, no mês de novembro.

"A história que eu conheço é que surgiram vários nomes para a escola. Aí, de repente a vó Ana pegou um vaso dela e mostrou dizendo 'esse vai ser o nome da escola'. Chego até a arrepiar contando a história”. (Depoimento de um sobrinho de Olívia)

A parceria entre a Coroa Imperial e a UNESP se deu através dos projetos de extensão Labsol e NeoCriativa. A Coroa Imperial encontrou na universidade um caminho para desenvolver seu Carnaval, unindo a universidade e a comunidade com o objetivo de gerar uma troca mútua de conhecimentos, técnicas e habilidades em processos criativos.

A parceria é fundamental para os alunos envolvidos, pois amplia a formação para além da sala de aula, levando-os a interagir na sociedade de forma direta e a construir a consciência social e vivenciar a experiência em contextos reais.

Nos anos de 2014 e 2015, a Coroa Imperial desfilou com cerca de 450 integrantes, dentre os quais diversos alunos. Cabe salientar que o sambódromo da cidade recebeu público estimado em 10 mil pessoas. Em termos quantitativos, a maior visibilidade de um projeto em Design Social em Bauru.

\section{Conclusão: por um Design vivo e cidadão}

As pedras de toque do Design Social são a participação e a colaboração. Quando conceitos em Design Social se inserem no Ensino, torna-se evidente a compreensão de que os projetos podem ser desenvolvidos em um ciclo de cooperação entre os agentes de criação, produção e uso a partir do primeiro vislumbre da possibilidade de realização de algo -tenha este algo se iniciado solitariamente na mente de um designer em seu estúdio ou sido gerado em brainstorming por um grupo de pessoas.

Em Design Social, da primeira ideia até a consecução do projeto, inclusive utilização, a autoria é dos agentes que deles participaram, compreendendo, seja o chão da fábrica, a loja (do cliente), seja a casa (do usuário).

Quando se fala em participação nesse contexto, fala-se em buscar opinião, ou seja, dar voz aos agentes envolvidos ao longo do processo, de modo que essa voz influencie no projeto e tenha efeitos sobre a forma final do objeto criado e produzido.

Até este ponto temos a junção da ideia de Design Social com a de Design Participativo. Posteriormente, vão surgindo outras denominações para caracterizar o processo de envolvimento dos agentes de criação, produção, circulação e uso. Em especial quando se pensa na questão de sustentabilidade planetária, quando se passou a conceber a fase de desuso, descarte do produto, bem como sua transformação em outros objetos, novos agentes adensaram essa cadeia de agentes.

Das posturas metodológicas surgidas dessa ideia de participação, colaboração e opinião, a mais recente e em voga seria mesmo a do Design Thinking, ligada à epistemologia.

Embora apareça nos fins dos anos sessenta do século XX, urdida por um economista, sociólogo e psicólogo, Herbert A. Simon, a ideia vai ganhar corpo nas engenharias com a noção de um brainstorm intensivo, em regime imersivo. São previstas fases de análise e 
síntese; compreende muitos croquis, esboços e utiliza a técnica do think aloud (quando o indivíduo pensa alto diante do grupo).

Cabe considerar que a noção de "Design" aqui, concebida por Simon, vem da língua inglesa e, portanto, não se refere exatamente ao conceito brasileiro de Design, mas sim a um "projeto de pensamento", ou seja, método de gerar soluções com criatividade e inovação. Não é à toa que Simon era psicólogo também. Assim, há que ser considerada a junção de suas expertises. Essa ideia de inovação, em princípio, remete-nos diretamente às engenharias, buscando adaptar novas soluções a necessidades e contexto concretos por meio de pessoas de equipes interdisciplinares. Note-se bem que se trata de engenharias, porém não mais enquanto área isolada.

Outra característica é que a busca feita pelo Design Thinking não parte do problema, com o aval da pragmática aplicada dos engenheiros, mas da solução, ou soluções, o que leva à junção da ideia de problema com a de necessidade; de problema com solução.

É pertinente lembrar que nos primórdios da metodologia em Design Social na PUC-Rio, não se utilizava o termo problema para o início do processo projetual, pois, nas artes, se pensava em um querer fazer ou em uma necessidade antes de tudo, independentemente de constituir, ou não, um problema.

Cabe lembrar que o surgimento do Design Thinking no século XX é importante nesse contexto. Na época, fez-se importante a busca de uma base científica para o Design, conforme apontado por Buchanan (1992). A preocupação era a da conexão e integração de conhecimentos entre as artes e as ciências de modo singular e adequado aos contextos.

Além disso, a cabeça do engenheiro tende à análise, enquanto um projeto de pensamento transcende ou subverte a análise enquanto método. Projetar com equipes transdisciplinares é projetar também com as formas de pensar características das ciências sociais e humanas. Estas gravitam em torno da síntese, que vem a ser perceber o todo, o conjunto sem a necessidade de análise a priori. Esta última também vai ser equacionada, porém não mais como ponto de partida.

Nesta linha de pensamento, a "tal arte", ou seja o Design permite aos indivíduos a participação direta quanto à questões de desenvolvimento social. Por outro lado, amplia possibilidades de investigar novas relações entre sinais, coisas, pensamentos e ações. Estes processos indicam para que o Design não seja somente considerado uma especialização técnica, mas uma "nova arte liberal".

Mas é preciso que se diga que foram os engenheiros e o setor produtivo que em primeiro lugar adotaram o Design Thinking em suas práticas. Talvez por causa da busca em criatividade, sentindo que seus métodos tradicionais exauriram as possibilidades de inovação. Essa noção de Design Thinking aliou-se à de Design Estratégico em empresas, aliado a administração e business (estes, tradicionalmente, têm um tom forte de racionalização, que não se sabe como se coadunam com o Design Thinking; talvez seja um racionalismo softcore, sem o clássico comportamento positivista das ciências físicas.).

Empresarialmente, o Design Thinking é considerado uma abordagem mental prática para acelerar a inovação. Promove a solução de problemas por meio de um olhar humano. Ao romper as barreiras da hierarquia e do pensamento exclusivamente cartesiano, o Design Thinking oferece espaço para as ideias emergirem sem pré-julgamentos, fazendo com que o cérebro saia da zona de conforto e, a partir daí, enxergue futuros desejáveis. 
O processo projetual para essa finalidade adota um tripé conceitual com base em: empatia, colaboração e experimentação.

Esses princípios são definidos da seguinte maneira:

- Empatia: significa colocar-se no lugar do outro, despir-se de pressupostos e compreender o contexto e ações do outro. Acolher, assimilar, acomodar perspectivas alheias;

- Colaboração: significa pensar conjuntamente, co-criar em equipes multidisciplinares para que nosso pensamento e capacidade de entendimento se multipliquem, e

- Experimentação: significa sair do campo das ideias, da fala. Testar soluções, experimentá-las para evitar problemas na fase de implementação.

A descrição não difere do proposto em termos do que é utilizado em Design Social, quando são definidos os instrumentos que um designer utiliza em uma determinada situação projetual. São identificados os pontos de vista de todos os participantes, considerando as questões que lhes dizem respeito e a projetação de um resultado final que se torna objeto para exploração e desenvolvimentos a posteriori.

É fato que na contemporaneidade também se fazem necessários questionamentos e reflexões acerca de ressignificações e limites de abrangências. Percebe-se que o Design assume a posição de ponto de partida quanto à intenção de transformar uma realidade existente em uma realidade desejada.

Observa-se um frescor quando os profissionais se deparam com a possibilidade de que muito além do resultado está o processo.

Necessário relembrar o eterno retorno aos princípios de Papanek (1977) que anunciava o momento de projetar como algo voltado para questões sociais. Predizia metodologias que poderiam ser aplicados em outras áreas e com propósitos os mais diversos. Há semelhança de conceitos do Design Social, tais como enunciados por diversos autores já citados, com a estruturação do que se configura como processos de projeto em Design Thinking.

A relevância na descrição dos processos e resultados neste artigo tem também a intenção de propor perguntas a fim de ampliarmos as possibilidades metodológicas em Design, colocando ação. A intenção é a de ir além de uma única possibilidade metodológica para projetos em Design, seja em qualquer denominação.

Finalmente, espera-se, mesmo aos poucos, que as reflexões nesse sentido penetrem nas redes do ensino e ampliem a multiplicidade de caminhos e possibilidades.

O Design Social é um Design junto com e não para com. Um princípio projetual em constante movimento. Por um Design Vivo e Cidadão.

\section{Referências}

Abbonizio, M. (2009). Aproximação teórica das intervenções de design no artesanato com os princípios pedagógicos de Paulo Freire: caminhos para uma prática emancipatória. Dissertação (Curso de Pós-Graduação em Design) - Universidade Federal do Paraná, Curitiba, Paraná, Brasil. 
Aquino, H. (2013). Alberto é a cara da Capoeira. A Voz da Capoeira. São Paulo: Casa da Capoeira.

Bardi, P. (1948). La experiènce didactique au Musée de Arte de São Paulo. Paris.

Bérgson, H. (1990). Matéria e Memória. São Paulo: Martins Fontes.

Blum, B. (1986). Oral History of Serge Chermayett. Chicago: The Art Institute of Chicago.

Boas, A. (2000). O que é e o que nunca foi Design Gráfico. Rio de Janeiro: 2Ab.

Bonfim, G. (1998). Ideias e formas na história do Design: uma investigação estética. João Pessoa: Editora Universitária - UFPB.

Bonsieppe, G. (1975a). Deseño Industrial: artefacto y proyeto. Madrid: Alberto Corazon.

Bonsieppe, G. (1978b). Teoria y practica del Diseño Industrial: elementos para una manualistica critica. Barcelona: G. Gilli.

Borges, A. (2003a). Designer não é personal trainer: e outros escritos. São Paulo: Rosari.

Borges, A. (2011b). Design + artesanato: o caminho brasileiro. São Paulo: Terceiro Nome.

Braga, M. C. (2011c). O papel social do Design Gráfico. São Paulo: SENAC.

Brandão, C. (Org.) (1984). Repensando a pesquisa participante. São Paulo: Brasiliense.

Brown, T. (2008). Design Thinking. Brighton: Harvard Business Review.

Buchanan, R. (1992). "Wicked Problems in Design Thinking", em Design Issues: The MIT Press (vol.8, n.2 pp 5-21). Recuperado em 18 dezembro 2013 de http://www.semantic foundry.com/docs/Buchanan_DesignThinking.pdf

Chaves, N. (2006). El Diseño Invisible - Siete Lecciones sobre La Intervención Culta en el Hábitat Humano. Buenos Aires: Editorial Paidós.

Coelho, L. (Org.) (2006). Design Método. Rio de Janeiro: PUC-Rio.

Couto, R. (2008a). Escritos sobre o ensino de Design no Brasil. Rio de Janeiro: RioBooks.

Couto, R. (1991b). O Ensino da Disciplina de Projeto Básico Sob o Enfoque do Design Social. Dissertação (Departamento de Educação) PUC-Rio.

Cranmer, J. e Zapatera, Y. (2003). Conscientious Objectives: designing for an ethical message. Londres: Rotovision.

Cross, N. (1972a). Design Participation. in Proceedings of the Design research Society. London: Academy Editions.

Cross, N. (1982b). Designerly ways of knowing. London: Design Studies, 1982.

Cunha, E. e Martins, B. (2011). "Design Social, o herói de mil faces, como condição para a atuação contemporânea", em Braga, M. O papel social do Design Gráfico. São Paulo: SENAC.

Cunha, G. (2015). O Gráfico amador: as origens da moderna tipografia brasileira. Rio de Janeiro: Verso Brasil Editora.

Deci, E. L. \& Ryan, R. M. (1985). Intrinsic motivation and self-determination in human behavior. New York: Plenum Press.

Denis, C. (2012). Design para um mundo complexo. São Paulo: Cosac Naify.

Droste, M. (1990). Bauhaus: 1919-1933. São Paulo: Taschen.

Escorel, A. (2000). O efeito multiplicador do Design. São Paulo: SENAC.

Ferrari, D. (2013). Somos todos um. Trabalho de Conclusão de Curso. (Graduação) Departamento de Design - UNESP, Bauru.

Findeli, A. (2001). "Rethinking Design education for the $21^{\text {st }}$ Century", em Design Issues MIT Press (vol. 17, n.1). 
Flusser, V. (2007). O mundo codificado: por uma filosofia do design e da comunicação. São Paulo: Cosac Naify.

Fornasier, C.; Martins, R.; e Merino, E. (2012). Da responsabilidade social imposta ao Design Social movido pela razão. Recuperado em 10 abril, 2013, de http://repositorio.ufsc.br/ bitstream/handle/123456789/1850

Frascara, J. (1997). Diseño Gráfico para la gente: Comunicaciones de masa y Cambio social. Buenos Aires: Ediciones Infinito y el Autor.

Freire, P. (1988a). “Criando métodos de pesquisa alternativa”, em Brandão, C. R. (Org.) Pesquisa participante. São Paulo: Brasiliense.

Freire, P. (2006b). Extensão ou comunicação? Rio de Janeiro: Paz e Terra.

García Canclini, N. (2006). Consumidores e Cidadãos: Conflitos Multiculturais da Globalização. Rio de Janeiro: Editora UFRJ.

Glaser, M. (2000). Art is Work. NY: Overlook Press.

Glaser, M. e Ilic, M. (2005). The Design of the Dissent. Massachusetts: Rockport.

Goya, C.; Toyama, A.; Silva, M.; Ochial M.; Toledo, N.; e Fernandes, T. (2011) “Laboratório de design solidário- LABSOL. Projeto de extensão em design na perspectiva da geração de trabalho e renda", em Rev. Ciênc. Ext. (v.7, n.3, p.7). Bauru: UNESP.

Imperial, C. (G.R.E.S) (2015). Material para Jurados de Carnaval. [Manual] Bauru, São Paulo, Brasil.

GIRLS, G. (1989). Confessions of the Guerrilla Girls. New York: GG.

Hall, S. (1997). "The work of representation", em Hall, S. Representation: cultural representations and signifying practices. London: Open University.

Heller, S. e Vienne, V. (2007). Citizen Designer: perspectives on Design responsibility. New York: Allworth Press.

Instalação do Instituto de Arte Contemporânea: o belo à serviço da indústria - o fundamento no desenho. São Paulo: Diário de São Paulo, 8 de março de 1950.

Latour, B. (1997a). Jamais fomos modernos. Rio de Janeiro: Ed. 34.

Latour, B. (2003b). A ciência em ação. Como seguir cientistas e engenheiros sociedade afora. São Paulo: Editora da Universidade Estadual Paulista.

Latour, B. (2005c). Reassembling the social. London: Oxford University Press.

Latour, B. e Hermant, E. (1998). Paris ville invisible. Paris: Institut Synthélabo.

Law, J. \& Urry, J. (2002). Enacting the social. UK: Department of Sociology/ Lancaster University.

Leite, J. (2003). A Herança do Olhar: o Design de Aloisio Magalhães. Rio de Janeiro: Artviva. Leon, E. (2014). IAC: Primeira Escola de Design no Brasil. São Paulo: Edgard Blucher.

Maldonado, T. (1993a). El diseño industrial reconsiderado. Barcelona: Gustavo Gilli.

Maldonado, T. (2012b). Cultura, Sociedade e Técnica. São Paulo: Blucher.

Langenbach, M. (2008). Além do apenas funcional. Inovação social e design de serviços na realidade brasileira. Dissertação. (Mestrado) - Programa de Pós-Graduação em Engenharia de Produção, Universidade Federal do Rio de Janeiro - UFRJ, Rio de Janeiro.

Manzini, E. (2008). Design para a inovação social e sustentabilidade: comunidades criativas, organizações colaborativas e novas redes projetuais. Rio de Janeiro: E-papers.

Margolin, V. (1997) The struggle for utopia. Chicago: University of Chicago Press. 
Margolin, V. e Margolin, S. (2002). A 'Social Model' of Design: issues of practice and research. Massachussets: MIT.

Meggs, P. (2009). História do Design Gráfico. São Paulo: Cosac Naify.

Meksenas, P. (2007). Sociologia da Educação: uma introdução ao estudo da escola no processo de transformação social. São Paulo: Edições Loyola.

Moraes, D. (2010). Metaprojeto: o design do design. São Paulo: Blucher.

Morin, E. (2000). Os sete saberes necessários à educação do futuro. São Paulo: Cortez.

Moura, M. (2014). Design brasileiro contemporâneo: reflexões. São Paulo: Estação das Letras e Cores.

Niemeyer, L. (2014a). Design no Brasil: origens e instalação. Rio de Janeiro: 2Ab, 1997.

Niemeyer, L. (2014b). Design: uma estratégia para o desenvolvimento humano. [Apostila da Aula Inaugural Departamento de Design.] São Paulo, Bauru: FAAC/UNESP.

Nobre, A. (2001). Carmem Portinho: o Moderno em Construção. São Paulo: Relume Dumará.

Pacheco, H. (1996a). O Design e Aprendizado: Barraca - quando o Design Social deságua no Desenho Coletivo. Dissertação. (Mestrado). Programa de Pós-Graduação em Design, Pontifícia Universidade Católica, Rio de Janeiro.

Pacheco, H. (2010b). "Involvement in the design student approach", Proceedings of Design Research Society's Conference DRS, 2010, Montreal.

Pacheco, H. e Toledo. G. (2012a). "A sparkle in people's eyes", $8^{\text {th }}$ International Conference Design History Society - ICDHS Proceedings. São Paulo: 2012.

Pacheco, H. \& Toledo. G. (2013b). “The word game: a Social Design research tool to visually communicate values, beliefs, and intrinsic motivation", $6^{\text {th }}$ Congresso Internacional de Design da Informação. CIDI. Recife.

Papanek, V. (1977). Diseñar para El Mundo Real: ecología humana y cambio social. Madrid: Hermann Blume.

Pazmino, A. V. (2007). Uma Reflexão sobre Design Social, Eco Design e Design Sustentável. Recuperado em 10 abril, 2013, de http://editorainsight.com.br/naolab/wp-content/ uploads/2012/03/PAZMINO2007-DSocial-EcoD-e-DSustentavel.pdf

Ryan, R. e Deci, E. (2000). "Intrinsic and extrinsic motivations: Classic definitions and new directions", em Contemporary Educational Psychology, 25:54-67.

Sanders, E. e Stappers, P. (2008). Co-creation and the new landscapes of design. CoDesign, Taylor \& Francis. Recuperado em 10 fevereiro, 2012, de http://desis-dop.org/documents $/ 10157 / 12818 /$ Sanders, + Stappers+\%282008\%29.+CoCreation++and+the+new+lands capes+of+design.pdf

Santa-Rosa, J. e Moraes, A. (2012) Design Participativo. Rio de Janeiro: RioBooks.

Santos, M. (2000). Por uma outra globalização: do pensamento único à consciência universal. São Paulo: Record.

Sodré, M. (2013). Reinventado a Educação: diversidade, descolonização e redes. Petrópolis: Vozes.

Souza, P. (1996). ESDI: biografia de uma ideia. Rio de Janeiro: EdUERJ.

Ware, C. (2008). Visual thinking for design Oxford. Morgan Kaufmann/Elsevier.

Ware, C. (2013). Information visualization: perception for design, 3ed. Waltham: Morgan Kaufmann/Elsevier.

Whiteley, N. (1993). Design for society. Londres: Reaktion Books. 
Whiteley, N. (1996). O designer valorizado. Rio de Janeiro: Revista Arcos EdUERJ.

Wollner, A. (2003). Design Visual 50 anos. São Paulo: Cosac \& Naify.

\begin{abstract}
The present paper puts on stage principles of Social Design applied to Education, Research, and Extension. It takes under consideration the practice of projects as an endactivity in Design. Thus the option for a didactic-pedagogical action through Social Design proposes the development of products together with social groups, and not for social groups. Acknowledging the multidisciplinary and hybrid character of Design, the research resorts to theoretical bases in several areas. It exemplifies results in real projects, developed and validated by students of "Curso de Graduação em Design FAAC/UNESP", between/within the years 2012 and 2014.
\end{abstract}

Key words: Education in Design - Project Disciplines - Curricular Reformulation.

Resumo: O presente artigo coloca em cena princípios do Design Social aplicados em Ensino, Pesquisa e Extensão. Considera-se a prática projetual como atividade-fim em Design. Dessa forma, a opção por ação didático-pedagógica no caminho do Design Social propõe atitude para desenvolvimento de produtos junto com grupos sociais, não para os grupos sociais. Reconhecido o caráter multidisciplinar e híbrido do Design, a pesquisa recorre a bases teóricas em áreas diversas. Exemplifica resultados em projetos concretos desenvolvidos e validados por estudantes do Curso de Graduação em Design FAAC/UNESP entre os anos de 2012 e 2014.

Palavras chave: Ensino em Design - Disciplinas de Projeto - Reformulação Curricular. 